\title{
Estratégia\&Negócios
}

ISSN 1984-3372

http://www.portaldeperiodicos.unisul.br/index.php/EeN/

\section{A EVIDENCIAÇÃO DA CULTURA ORGANIZACIONAL VOLTADA PARA A RESPONSABILIDADE AMBIENTAL}

\section{ENVIRONMENTAL DISCLOSURE: A STUDY ABOUT EVOLUTION IN COMPANIES COMPRISING THE ENVIRONMENTAL SUSTAINABILITY INDEX}

\section{Irani Rocha}

Mestranda do Programa de Pós-Graduação em Ciências Contábeis da Universidade Regional de Blumenau - FURB Email: irocha@al.furb.br

\section{Sabrina do Nascimento}

Mestranda do Programa de Pós-Graduação em Ciências Contábeis da Universidade Regional de Blumenau - FURB Email: sabnascimento@gmail.com

\section{Júlio Orestes da Silva}

Mestrando do Programa de Pós-Graduação em Ciências Contábeis da Universidade Regional de Blumenau - FURB Email: juliosilva@al.furb.br

\section{Rony Petson Santana de Souza}

Mestrando do Programa de Pós-Graduação em Ciências Contábeis daUniversidade Regional de Blumenau - FURB Email: ronypetson@al.furb.br

\section{Denise Del Prá Netto Machado}

Professora do Programa de Pós-Graduação em Administração e Ciências Contábeis da Universidade Regional de Blumenau - FURB

Email: delpra@furb.br

Recebido em 10/11/2010. Aprovado em 25/04/2011. Disponibilizado em 20/10/2011. Avaliado pelo Sistema double blind review

R. eletr. estrat. neg., Florianópolis, v.4, n.1, p.108-132, jan./jun. 2011 http://portaldeperiodicos.unisul.br/index.php/EeN/index
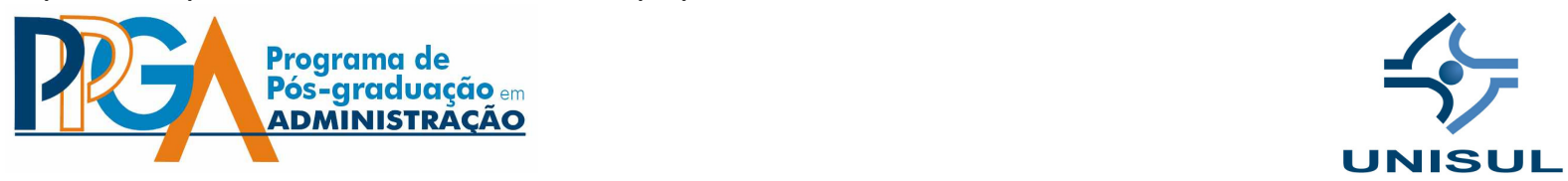

CCopyright 2008 UNISUL-PPGA/Estratégia e Negócios. Todos os direitos reservados. Permitida citação parcial, desde que identificada a fonte. Proibida a reprodução total. Em caso de dúvidas, consulte o editor: gabriela.fiates@unisul.br; (48) 3229-1932. 


\section{RESUMO}

Esta pesquisa teve por objetivo verificar a evolução do disclosure ambiental nas organizações que compõem o ISE desde a sua primeira formação. Na metodologia, optou-se por uma pesquisa descritiva, por meio de uma análise de conteúdo com uma abordagem qualitativa e quantitativa. Apresentando como sustentação teórica uma rápida abordagem sobre Gestão Ambiental, Índice de Sustentabilidade Ambiental (ISE) e Categorias Culturais e Variáveis Ambientais. Desenvolveu-se um modelo com base nos indicadores de responsabilidade social empresarial do Instituto Ethos (2009) e, posteriormente, as empresas foram organizadas em rankings, aplicando-se a Analytic Hierarchy Process (AHP). A amostra constitui-se das empresas que compõem o ISE da BM\&FBovespa desde o início, totalizando 14 empresas participantes. Os resultados demonstram que em 2006 ocorreu aumento significativo de evidenciação por parte das empresas. Constatou-se um aumento contínuo na divulgação de informações que demonstram a preocupação das empresas com relação ao meio ambiente, atendendo, assim, as demandas da sociedade, respaldando sua crescente cobrança por transparência nas atitudes relacionadas ao meio ambiente. Desta forma, incorporando-se a cultura da empresa, sendo operacionalizada e evidenciada pela organização. Os rankings revelam que as empresas apresentaram um índice de evidenciação maior nos sites, muito superiores às informações dos relatórios da administração. Infere-se ainda que as companhias utilizam suas homepages para expressar suas atitudes e projetos relacionados à gestão ambiental.

Palavras-chave: Disclosure ambiental. Responsabilidade ambiental. Índice de Sustentabilidade Empresarial.

\section{INTRODUÇÃO}

As organizações vêm sofrendo cada vez mais cobrança da sociedade quanto à prestação de contas no sentido de identificar aquelas entidades que geram prejuízos ou que não acrescentam valor à qualidade de vida da comunidade onde estão inseridas (AZEVEDO; CRUZ, 2006). Trata-se de atividades, atitudes, projetos, ações desenvolvidas pelas organizações que impactam no meio ambiente. Para Rover, Borba e Borgert (2008) esses impactos que as empresas 
causam ao meio ambiente acabam refletindo no mercado em que atuam e na imagem dessas perante a opinião pública.

Para minimizar alguns impactos que podem ser causados por decisões relacionadas ao meio ambiente, as empresas optam por divulgar as informações em seus relatórios. As entidades incorporam a questão ambiental, adotando sistemas de gestão ambiental e investindo em procedimentos que reduzam os impactos que suas atividades causam ao meio ambiente. Calixto (2006) destaca que a divulgação voluntária das ações sociais e ambientais, por meio dos relatórios das empresas, tornou-se frequente e necessária, pois em períodos de competição, em que a conscientização envolvendo temas ambientais surgem e permanecem em foco, as atenções nas divulgações tendem a voltar-se a questões que no passado não ganhavam grande destaque.

As informações ambientais são evidenciadas pelas empresas e possuem o objetivo de "identificar, mensurar e esclarecer os eventos e transações econômico-financeiros que estejam relacionados com a proteção, preservação, e recuperação ambiental, ocorridos em um determinado período, visando à evidenciação da situação patrimonial da entidade" (RIBEIRO, 2005, p. 45). Para Aquino e Santana (1992), evidenciar significa divulgar as informações com clareza, de maneira que se compreenda imediatamente o que está sendo comunicado.

Com a evidenciação ambiental, torna-se possível observar a cultura da organização, pois de acordo com Machado e Giombelli (1997) a partir do momento que a variável ambiental for operacionalizada entre os membros da organização, ela passa a fazer parte da sua cultura. Essa operacionalização se faz por meio de técnicas e políticas que visam à preservação do meio ambiente, ou seja, observa-se a preocupação com resíduos, materiais, energia, água, transporte e gestão (INSTITUTO ETHOS, 2009).

As empresas comprometidas com a responsabilidade social e sustentabilidade empresarial buscam participar do Índice de Sustentabilidade Empresarial (ISE) da BM\&FBovespa. Este índice mede o retorno total de uma carteira teórica composta por ações de empresas socialmente responsáveis.

A evidenciação de informações relacionadas com as questões ambientais tem sido muito debatida na literatura acadêmica, na qual se procura observar a relevância do tema nos relatórios apresentados pelas empresas. Assim, esta pesquisa aborda o tema da gestão ambiental e cultura organizacional nas empresas que fazem parte do Índice de Sustentabilidade Empresarial (ISE) da BM\&FBovespa desde sua criação. Dessa forma, emerge a indagação que norteia o 
presente estudo: Qual é a evolução do disclosure ambiental nas organizações que compõem o Índice de Sustentabilidade Empresarial (ISE) desde a sua primeira formação?

O objetivo desta pesquisa é verificar a evolução do disclosure ambiental nas organizações que compõem o Índice de Sustentabilidade Empresarial (ISE) desde a sua primeira formação. Para alcançar o objetivo geral, são traçados alguns objetivos específicos: a) caracterizar os segmentos e o nível de governança corporativa predominante entre as empresas que compõem a amostra; b) identificar as informações evidenciadas, segundo a categorização adaptada do Instituto Ethos; c) estabelecer rankings das empresas segundo o nível de evidenciação ambiental nos relatórios de administração e sites das organizações; d) verificar a evidenciação ambiental e relacionar a evolução do disclosure aos artefatos físicos da cultura organizacional nas empresas que participam do ISE desde o início.

\section{GESTÃO AMBIENTAL}

A sociedade tem se mobilizado e exigido uma postura diferenciada das empresas, em especial das empresas com atividades potencialmente poluidoras, atitudes com relação à preservação do meio ambiente, no sentido de educação, treinamento de funcionários, iniciativas que possam contribuir para melhora na qualidade de vida (CALIXTO, 2006). Diante dessa situação, as organizações têm consciência de que para alcançar um bom desempenho e se manter no mercado competitivo, a responsabilidade social merece uma atenção especial, necessitando adaptá-la à estratégia empresarial (GONÇALVES; HELIODORO, 2005).

De acordo com Wernke (2001), um dos diferenciais que proporciona à empresa o destaque no mercado é a variável ambiental. Observa-se que grandes empresas começaram a visualizar os gastos com proteção ambiental como investimento e vantagem competitiva e não como um custo (ANDRADE; TACHIZAWA; CARVALHO, 2002).

Com o objetivo de adaptar a gestão das organizações aos conceitos e compromissos que propiciem o desenvolvimento sustentável, foi desenvolvido pelo Instituto Ethos (2009) uma série de indicadores de responsabilidade social. Dentre os indicadores desenvolvidos voltados para o meio ambiente, tem-se: a) compromisso com a melhoria da qualidade ambiental; b) educação e conscientização ambiental; c) gerenciamento dos impactos sobre o meio ambiente e 
do ciclo de vida de produtos e serviços; d) sustentabilidade da economia florestal e e) minimização de entradas e saídas de materiais (SILVEIRA, 2008). A Figura 1 apresenta o mapa de gestão ambiental e meio ambiente com suas respectivas categorias e indicadores adaptado do Instituto Ethos.

Figura 1: Mapa de Gestão Ambiental - Meio Ambiente

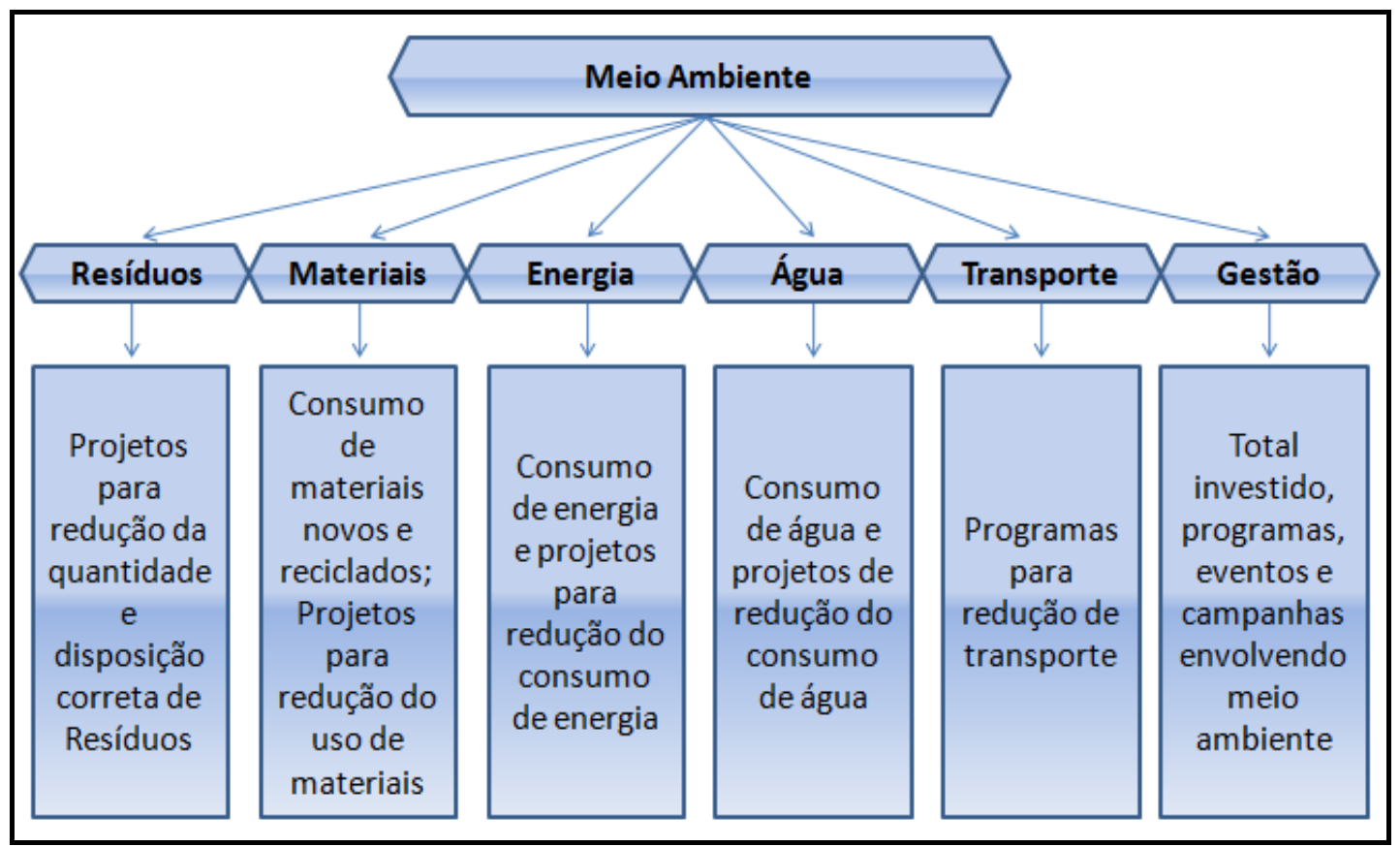

Fonte: Adaptado do Instituto Ethos (2009).

$\mathrm{Na}$ Figura 1, observam-se as cinco categorias que possibilitam a mensuração do compromisso da organização com relação ao meio ambiente que contemplam as ações de educação ambiental, minimização no descarte de resíduos, forma de utilização de recursos naturais não renováveis (como consumo de energia e água), participação de materiais usados provenientes de reciclagem e reutilização de materiais.

De acordo com Valle (2004), os resíduos representam um dos maiores riscos ambientais. Para minimizar tais riscos, como os resíduos não são nocivos, eles podem ser reaproveitados e transformados em subprodutos ou matéria prima para outra linha de produção. Infere-se ainda que a grande preocupação com os resíduos reside na maneira em que eles são dispostos, na geração acelerada e no esgotamento da capacidade de aterro (MOREIRA, 2006).

Segundo Moreira (2006), a redução do uso da energia fornecida por fontes não renováveis (petróleo, gás e carvão) é a principal preocupação, em contra partida ao desenvolvimento de fontes alternativas de geração de energia de forma que se evite a construção de novas usinas hidrelétricas e nucleares. Acredita-se que a energia é um insumo importante em 
todos os produtos consumidos pela população, considera-se que a utilização da energia está diretamente ligada à vida da humanidade (MOURA, 2008).

A grande preocupação com relação à água é a contaminação dos oceanos, a qualidade e manutenção da água para utilização da sociedade. A superfície terrestre é $74 \%$ composta por água, sendo somente $0,8 \%$ disponível para o consumo humano (MOREIRA, 2006).

O transporte é um dos maiores poluentes do ar, atitudes com relação ao controle desse poluente deverão ser tomadas, pois eles estão ligados diretamente à qualidade de vida, na geração de doenças entre outras consequências (MOURA, 2008).

A partir dos anos 90, iniciou uma nova fase com relação à gestão ambiental nas organizações. Observa-se uma maior preocupação com relação à sustentabilidade, a implantação de código de conduta, convênios e acordos voluntários, maior interação com empresas públicas e privadas resultando na escolha de instrumentos de política ambiental (CARAZZA, 2003).

\section{3 ÍNDICE DE SUSTENTABILIDADE EMPRESARIAL (ISE)}

A procura por empresas socialmente responsáveis no gerenciamento de seus recursos é uma tendência mundial que há alguns anos tem se manifestado por parte dos investidores. Acredita-se que essas empresas socialmente responsáveis estão mais preparadas para enfrentar os riscos econômicos, sociais e ambientais, considera-se ainda que estas consequentemente geram valor para seus acionistas no longo prazo (BOVESPA, 2009). Essa tendência está cada vez mais forte em meio à globalização, além das informações obrigatórias, as organizações que buscam captar novos investidores passam a divulgar informações adicionais com relação à gestão empresarial e ações de responsabilidade social e ambiental. Sendo essas informações financeiras ou não financeiras (VAZ et al., 2008).

Corroborando com essa tendência foi criado pela BM\&FBovespa, juntamente com outras instituições, um índice referencial para os investimentos socialmente responsáveis, o Índice de Sustentabilidade Empresarial (ISE) (BOVESPA, 2009). Criado em meados de 2005, tem como conceito básico Triple Botton Line (TBL), juntamente com critérios de governança corporativa, seguindo o índice da Bolsa de Johannesburg (JSE). O objetivo deste índice é despertar a 
responsabilidade ética das corporações e ser um ambiente de investimento. (REZENDE; SANTOS, 2006).

A Bovespa (2009) considera o Índice de Sustentabilidade Empresarial "um índice que mede o retorno total de uma carteira teórica composta por ações de empresas com reconhecido comprometimento com a responsabilidade social e a sustentabilidade empresarial (no máximo 40)." Nesse sentido, são selecionadas as ações mais negociadas na BM\&FBovespa com relação à liquidez, sendo ponderadas na carteira pelo valor de mercado das ações disponíveis à negociação.

As empresas participantes do ISE passam por um critério de avaliação feito por meio de questionários. Estes questionários são analisados por agências e/ou empresas especializadas, que consolidam, organizam e conferem as informações prestadas pelas empresas (GONÇALVES; PIRANI; BORGER, 2007). O conselho deliberativo, presidido pela BM\&FBovespa é quem seleciona as empresas que apresentarem melhor classificação. Estão inclusos na avaliação elementos ambientais, sociais e econômico-financeiros, acrescidos a mais três grupos de indicadores: a) critérios gerais; b) critérios de natureza do produto; e c) critérios de governança corporativa. Cabe ressaltar ainda que o preenchimento do questionário (com apenas perguntas objetivas) é voluntário, demonstrando o comprometimento da empresa com as questões de sustentabilidade, consideradas cada vez mais importantes no mundo todo (BOVESPA, 2009).

\section{CATEGORIAS CULTURAIS E VARIÁVEIS AMBIENTAIS}

Na década de 80, observou-se um forte discurso com relação à cultura organizacional (FREITAS, 1991). Assim, a cultura é entendida como um sistema adaptativo de acordo com alguns trabalhos como os de Leslie White, Sahlins, Harris, Carneiro, Rappaport, Vayda (Laraia, 2002). Trompenaars (1994, p.143) destaca que Cultura Organizacional "compreende não apenas tecnologias e mercados, mas preferências culturais de líderes e empregados." Laraia (2002) considera que o homem é o herdeiro de um processo cumulativo, proveniente de gerações que o antecedem e reflete o conhecimento e a experiência adquirida. O autor afirma que "o homem é o resultado do meio cultural em que foi socializado" (LARAIA 2002, p. 45).

Aléssio et al. (2009) entendem que a maneira como a organização se estrutura reflete em seus colaboradores, em suas crenças e valores. O clima organizacional é formado pelo 
relacionamento das instituições com as pessoas que as estruturam e com os relacionamentos das pessoas entre si. Para Freitas (1991, p.XVII), cultura organizacional pode ser entendida "como um forte mecanismo que visa conformar condutas, homogeneizar maneiras de pensar e viver a organização, introjetar uma imagem positiva da mesma, onde todas são iguais, escamoteando as diferenças e anulando a reflexão." Na mesma linha dos autores, Machado (2004, p.35) define cultura como sendo "um sistema de significados aceito pelos integrantes da organização em um determinado tempo e serve de base para a interpretação das situações do cotidiano."

A Cultura Organizacional pode ser descrita por elementos que a constituem, tais como: missão, visão, políticas, regras, normas, crenças e valores (FREITAS, 1991). Tavares (1996) destaca que os elementos são importantes para direcionar e legitimar as atitudes dos membros de uma organização. Os elementos ou artefatos da Cultura Organizacional direcionam o comportamento do grupo. Corroborando com essa definição, Machado (2004, p.43) menciona que:

Os artefatos culturais representam a forma concreta da cultura de uma organização. São os instrumentos materiais utilizados para direcionar a cultura organizacional, dando estimulação sensorial para executar atividades culturalmente expressas. Têm por objetivo disseminar a cultura dentro da organização. Classificam-se em ritos, rituais e cerimônias, estórias e mitos, heróis, tabus, normas, comunicação e símbolos.

Os artefatos culturais são meios de comunicação, pelos quais são transmitidas as regras da organização como também facilitam a socialização na organização (SMIRCICH, 1983). O Quadro 1 apresenta uma síntese dos artefatos culturais. De acordo com Machado (2004, p.58), “a utilização de artefatos determina uma estratégia para que os membros se adaptem à cultura vigente e às suas mudanças".

\section{Quadro 1: Classificação dos artefatos culturais}

\begin{tabular}{|c|c|}
\hline Artefatos verbais & $\begin{array}{l}\text { A cultura na organização torna-se consistente por meio da história e trajetória da } \\
\text { mesma. A história contempla comportamentos, situações, atitudes, direito e } \\
\text { deveres de todos os membros que a compõem (FREITAS, 1991). Como artefatos } \\
\text { verbais referem-se à história, à origem da organização, à comunicação, nesse } \\
\text { sentido, também diz respeito ao comportamento, às atitudes, à explicação } \\
\text { referente ao pensar e agir dos membros pertencentes à organização. Considera-se } \\
\text { relevante a visão que as organizações buscam transmitir ao público interno e } \\
\text { externo a ela, a visão de constituírem uma grande família, ou seja, a camaradagem, } \\
\text { confiança, trabalho cooperado, trabalhando com o mesmo objetivo para o sucesso } \\
\text { da empresa (MACHADO, 2004). Quando se fala família, imagina-se um grupo } \\
\text { definido com uma cultura própria, formada por suas crenças e valores. Dentro dessa } \\
\text { família estão os valores da organização com relação ao meio ambiente e à } \\
\text { preservação ambiental. Nas organizações, são identificadas pessoas que transmitem } \\
\text { conceitos sobre preservação ambiental, pessoas consideradas um exemplo a ser } \\
\text { seguido, pessoas que mostram a importância e buscam influenciar os demais } \\
\text { membros que as compõem (KILMAN, et al, 1988, apud MACHADO e GIOMBELLI, } \\
\text { 1997). }\end{array}$ \\
\hline $\begin{array}{c}\text { Artefatos } \\
\text { Comportamentais }\end{array}$ & $\begin{array}{l}\text { Artefatos comportamentais referem-se à maneira de comunicar as regras, } \\
\text { atividades planejadas pela organização com relação a todos envolvidos (MACHADO, }\end{array}$ \\
\hline
\end{tabular}




\begin{tabular}{|c|c|}
\hline & $\begin{array}{l}\text { 2004). Nessas atividades, incluem jogos, festas, gincanas, treinamento e seminários, } \\
\text { atividades que movimentam ações e possibilitam a conscientização dos funcionários } \\
\text { com relação à preservação ambiental (KILMAN et al., 1988, apud, MACHADO e } \\
\text { GIOMBELL, 1997). Nesse sentido, possibilita a criação de uma cultura forte } \\
\text { (MACHADO, 2004). }\end{array}$ \\
\hline Artefatos Físicos & $\begin{array}{l}\text { Artefatos Físicos são considerados a arte da organização, ou seja, normas e símbolos } \\
\text { que representam a cultura da empresa, possibilitando aos membros da organização } \\
\text { ouvir, ver, sentir, incorporar a cultura que está inserida (MACHADO, 2004). Fazem } \\
\text { parte desse artefato os documentos, jornais de circulação, folders, cartazes, ou seja, } \\
\text { informativos que evidenciam a preocupação da organização com relação ao meio } \\
\text { ambiente (KILMAN et al., } 1988 \text { apud MACHADO e GIOMBELL, 1997). }\end{array}$ \\
\hline
\end{tabular}

Fonte: Elaborado pelos autores.

Makower (1994) destaca que a atitude dos funcionários, aquilo que é feito na organização, acaba refletindo interna e externamente, atingindo os consumidores, a comunidade no geral e o meio ambiente. Mello Neto e Froes (1999) complementam tal ideia ao considerarem que essa abrangência acaba envolvendo toda sociedade, governo, empresa, grupos sociais, como igreja, movimentos sociais, partidos políticos e outras instituições. Infere-se que a atitude dos colaboradores em uma empresa terá como base a cultura organizacional que a envolve, ou seja, os artefatos verbais, comportamentais e físicos do ambiente organizacional.

Leite, Ribeiro e Pacheco (2007) destacam a importância da divulgação de informações no sentido de proporcionar uma visão abrangente e mais clara da organização para as tomadas de decisões por parte dos usuários externos à organização. Dentre as informações divulgadas, estão as informações sobre o impacto ambiental e o desempenho operacional de uma entidade. Segundo Gray e Bebbington (2001), a cultura organizacional é que define o nível de evidenciação ambiental nos relatórios de uma organização.

Frente às exigências da sociedade com relação ao meio ambiente, Machado e Giombelli (1997) destacam que "a variável ambiental foi operacionalizada através da identificação de técnicas e políticas que visam à preservação do meio ambiente". Dentre essas técnicas e políticas, encontra-se a preocupação com resíduos, materiais, energia, água, transporte e gestão, conforme aborda o Instituto Ethos (2009).

\section{MÉTODOS E PROCEDIMENTOS DA PESQUISA}

A presente pesquisa utiliza abordagem descritiva. Raupp e Beuren (2008, p. 81) destacam que pesquisas desta natureza caracterizam-se "como um estudo intermediário entre a 
pesquisa exploratória e a explicativa, ou seja, não é tão preliminar como a primeira e não tão aprofundada como a segunda". Para Triviños (1987), o estudo descritivo requer delimitações de técnicas, métodos, modelos e teorias.

Quanto à abordagem do problema, esta pesquisa classifica-se como quantitativa e qualitativa. Os aspectos quantitativos consistem no "emprego de quantificação tanto nas modalidades de informações, quanto no tratamento delas por meio de técnicas estatísticas" (RICHARDSON, 1989, p. 70), sendo que procurou-se verificar as informações relacionadas à gestão ambiental evidenciadas nos relatórios de administração e notas explicativas das empresas que compõem o Índice de Sustentabilidade Empresarial (ISE), quantificando as mesmas e analisandoas estatisticamente. A parte qualitativa caracteriza-se pela análise de conteúdo dos relatórios da administração e sites das empresas que compõem a amostra. Para Bardin (2004, p.37) análise de conteúdo é entendida como "um conjunto de técnicas de análise das comunicações, visando obter, por procedimentos sistemáticos e objetivos de descrição do conteúdo [...] que permitem a inferência de conhecimentos relativos [...] destas mensagens". Nossa (2002, p. 172) destaca que "a análise de conteúdo é uma das várias técnicas que pode ser utilizada na análise de textos".

A amostra deste estudo constitui-se das empresas que compõem o Índice de Sustentabilidade Empresarial (ISE) da Bolsa de Valores de São Paulo (BOVESPA), desde sua criação, sendo assim estas empresas fazem parte das quatro formações do ISE nos anos de 2006, 200, 2008 e 2009, explicitadas no Quadro 2.

Quadro 2: Amostra da pesquisa

\begin{tabular}{|c|l|l|l|}
\hline COD. & \multicolumn{1}{|c|}{ EMPRESA } & \multicolumn{1}{|c|}{ SEGMENTO } & \multicolumn{1}{c|}{ NÍVEL } \\
\hline 1 & CEMIG & Energia Elétrica & Nível 1 \\
\hline 2 & ELETROPAULO & Energia Elétrica & Nível 2 \\
\hline 3 & CPFL ENERGIA & Energia Elétrica & Novo Mercado \\
\hline 4 & TRACTEBEL & Energia Elétrica & Novo Mercado \\
\hline 5 & BRADESCO & Bancos & Nível 1 \\
\hline 6 & ITAUUNIBANCO & Bancos & Nível 1 \\
\hline 7 & BCO BRASIL & Bancos & Novo Mercado \\
\hline 8 & SUZANO PAPEL & Papel e Celulose & Nível 1 \\
\hline 9 & V C P & Papel e Celulose & Nível 1 \\
\hline 10 & PERDIGAO S/A & Carnes e Derivados & Novo Mercado \\
\hline 11 & DASA & Serv. Médicos-Hospitalares & Novo Mercado \\
\hline 12 & EMBRAER & Material Aeronáutico & Novo Mercado \\
\hline 13 & BRASKEM & Petroquímicos & Nível 1 \\
\hline 14 & NATURA & Produtos de Uso Pessoal & Novo Mercado \\
\hline
\end{tabular}

Fonte: Dados da pesquisa. 
No Quadro 2, percebe-se que no ISE nos anos de 2008 e 2009, constam 14 empresas que estão em todas as formações deste indicador nos últimos quatro anos. Cabe mencionar que estas empresas destacaram-se neste período pelo comprometimento com a responsabilidade social e sustentabilidade empresarial.

$\mathrm{Na}$ etapa de coleta dos dados, as buscas foram realizadas nos relatórios de administração (RAs) destas empresas no período de 2005 a 2008 disponíveis no site da Bovespa e nas homepages das empresas analisadas. Na primeira fase de coleta das informações, quantificaram-se os trechos dos RAs e das homepages das empresas pesquisadas para identificar as seguintes palavras: resíduos, materiais, energia, água, transporte e gestão, ou seja, estas palavras compreendem as categorias que correspondem ao constructo das estratégias de análise da evidenciação ambiental, elaboradas com base nos indicadores de responsabilidade social empresarial do Instituto Ethos (2009), conforme o Quadro 3.

Quadro 3: Estratégias de análise da evidenciação ambiental

\begin{tabular}{|l|}
\hline CATEGORIA 1: RESÍDUOS \\
\hline 1.1 - Gastos com destinação de resíduos ou quantidade de resíduos gerada \\
\hline 1.2 - Projetos para disposição correta de resíduos \\
\hline 1.3 - Projetos de redução da quantidade de resíduos \\
\hline 1.4 - Reaproveitamento dos Resíduos \\
\hline CATEGORIA 2: MATERIAIS \\
\hline 2.1 - Reciclagem de materiais \\
\hline 2.2 - Consumo de materiais novos, escolhas alternativas para reduzir os impactos ambientais \\
\hline 2.3 - Consumo de materiais reciclados \\
\hline 2.4 - Projetos para redução da utilização de materiais \\
\hline CATEGORIA 3: ENERGIA \\
\hline 3.1 - Consumo de energia \\
\hline 3.2 - Fontes alternativas de energia, causando menos impactos ambientais \\
\hline 3.3 - Projetos para redução do consumo de energia \\
\hline 3.4 - Readequação dos ambientes para utilizar mais luz solar \\
\hline CATEGORIA 4: ÁGUA \\
\hline 4.1 - Consumo de água \\
\hline 4.2 - Projetos de redução do consumo de água \\
\hline 4.3 - Estações de tratamento de água \\
\hline CATEGORIA 5: TRANSPORTE \\
\hline 5.1 - Gastos com transporte \\
\hline 5.2 - Programas de incentivo aos transportes de massas \\
\hline 5.3 - Opç̃̃es alternativas de transporte ambientalmente responsáveis \\
\hline 5.4 - Implantação e utilização de tecnologia para substituição de deslocamento para reuniões \\
\hline CATEGORIA 6: GESTÃO \\
\hline 6.1 - Sistema de gestão ambiental \\
\hline 6.2 - Total investido no meio ambiente \\
\hline 6.3 - Programas de educação ambiental \\
\hline 6.4 - Campanhas de coleta seletiva envolvendo a sociedade \\
\hline 6.3 - Eventos envolvendo a proteção ambiental \\
\hline
\end{tabular}


Fonte: Adaptado do Instituto Ethos (2009).

O Quadro 3 apresenta as categorias analisadas e suas subdivisões. A partir dessas categorias, investigaram-se as ações implementadas pelas empresas analisadas, com relação ao consumo de recursos renováveis e não renováveis; ações para redução e melhorias na destinação de resíduos; ações de redução do consumo de materiais; ações de conservação de energia; ações para redução do consumo de água; medidas para reduzir transporte e gestão ambiental.

Na segunda fase, foi interpretado o trecho onde a palavra estava inserida, buscando identificar se estava relacionada ao contexto da pesquisa. Averiguando-se a relação, aplicou-se a técnica de análise de conteúdo. Assim, cada subcategoria investigada poderia ser pontuada apenas uma vez, independentemente se o contexto da mesma fosse evidenciado mais vezes nos documentos investigados.

Em seguida, foram atribuídas pontuações para os itens evidenciados, sendo zero (0) quando a empresa não evidenciava e um (1) para os itens que a empresa evidenciava e estava de acordo com o modelo proposto. Na sequência, os dados coletados foram organizados em quadros, para análise da evidenciação das informações de gestão ambiental.

A Tabela 1 exemplifica a tabela com a pontuação alcançada pelas empresas pesquisadas por meio da análise dos sites.

Tabela 1: Resultado da análise de conteúdo alcançada nos sites das empresas

\begin{tabular}{|l|r|r|r|r|r|r|r|r|r|r|r|r|r|r|r|r|r|r|r|r|r|r|r|r}
\hline \multicolumn{1}{c|}{ EMPRESAS } & V1 & V2 & V3 & V4 & V5 & V6 & V7 & V8 & V9 & V10 & V11 & V12 & V13 & V14 & V15 & V16 & V17 & V18 & V19 & V20 & V21 & V22 & V23 & V24 \\
\hline CEMIG & 2 & 2 & 2 & 2 & 2 & 1 & 2 & 1 & 1 & 2 & 2 & 2 & 1 & 1 & 2 & 1 & 1 & 1 & 1 & 2 & 2 & 2 & 2 & 2 \\
\hline ELETROPAULO & 1 & 2 & 2 & 1 & 1 & 1 & 1 & 2 & 1 & 2 & 1 & 1 & 1 & 1 & 1 & 1 & 1 & 1 & 1 & 2 & 2 & 2 & 1 & 1 \\
\hline CPFL ENERGIA & 1 & 2 & 2 & 2 & 2 & 1 & 2 & 2 & 1 & 2 & 2 & 1 & 1 & 1 & 1 & 1 & 1 & 2 & 1 & 2 & 1 & 2 & 1 & 2 \\
\hline TRACTEBEL & 1 & 2 & 2 & 2 & 2 & 1 & 2 & 1 & 1 & 2 & 1 & 1 & 1 & 1 & 2 & 1 & 1 & 1 & 1 & 1 & 2 & 2 & 1 & 2 \\
\hline BRADESCO & 1 & 2 & 2 & 2 & 2 & 1 & 2 & 2 & 1 & 2 & 2 & 1 & 1 & 2 & 1 & 1 & 1 & 1 & 1 & 1 & 1 & 2 & 1 & 2 \\
\hline ITAUUNIBANCO & 1 & 1 & 1 & 1 & 1 & 1 & 1 & 1 & 1 & 1 & 1 & 1 & 1 & 1 & 1 & 1 & 1 & 1 & 1 & 1 & 1 & 1 & 1 & 1 \\
\hline BCO BRASIL & 1 & 1 & 1 & 1 & 1 & 1 & 1 & 1 & 1 & 1 & 1 & 1 & 1 & 1 & 1 & 1 & 1 & 1 & 1 & 1 & 1 & 1 & 1 & 1 \\
\hline SUZANO PAPEL & 1 & 2 & 2 & 2 & 2 & 1 & 2 & 1 & 1 & 2 & 2 & 1 & 2 & 2 & 2 & 1 & 1 & 1 & 1 & 2 & 2 & 2 & 1 & 2 \\
\hline V C P & 1 & 1 & 1 & 1 & 1 & 1 & 1 & 1 & 1 & 1 & 1 & 1 & 1 & 1 & 1 & 1 & 1 & 1 & 1 & 1 & 1 & 1 & 1 & 1 \\
\hline PERDIGAO S/A & 1 & 1 & 1 & 1 & 1 & 1 & 1 & 1 & 1 & 1 & 1 & 1 & 1 & 1 & 1 & 1 & 1 & 1 & 1 & 1 & 2 & 1 & 1 & 1 \\
\hline DASA & 1 & 1 & 1 & 1 & 1 & 1 & 1 & 1 & 1 & 1 & 1 & 1 & 1 & 1 & 1 & 1 & 1 & 1 & 1 & 1 & 2 & 1 & 1 & 1 \\
\hline EMBRAER & 2 & 2 & 2 & 2 & 2 & 1 & 2 & 2 & 1 & 2 & 2 & 1 & 2 & 2 & 2 & 1 & 1 & 1 & 1 & 1 & 1 & 1 & 1 & 1 \\
\hline BRASKEM & 1 & 2 & 2 & 1 & 1 & 1 & 1 & 2 & 2 & 1 & 2 & 1 & 1 & 2 & 2 & 1 & 1 & 1 & 1 & 1 & 2 & 2 & 1 & 2 \\
\hline NATURA & 1 & 2 & 2 & 1 & 2 & 1 & 1 & 2 & 1 & 2 & 2 & 1 & 1 & 2 & 2 & 1 & 1 & 1 & 1 & 1 & 1 & 2 & 1 & 1 \\
\hline \multicolumn{1}{c|}{ TOTAL } & 16 & 23 & 23 & 20 & 21 & 14 & 20 & 20 & 15 & 22 & 21 & 15 & 16 & 19 & 20 & 14 & 14 & 15 & 14 & 18 & 21 & 22 & 15 & 20 \\
\hline \multicolumn{1}{c|}{ MÉDIA } & 1,1 & 1,6 & 1,6 & 1,4 & 1,5 & 1 & 1,4 & 1,4 & 1,1 & 1,6 & 1,5 & 1,1 & 1,1 & 1,4 & 1,4 & 1 & 1 & 1,1 & 1 & 1,3 & 1,5 & 1,6 & 1,1 & 1,4 \\
\hline
\end{tabular}

Fonte: Dados da pesquisa.

A terceira fase compreendeu a utilização do método estatístico Analytic Hierarchy Process (AHP), que permitiu a criação de um ranking das empresas que evidenciaram as informações ambientais ao longo dos períodos analisados. De acordo com Nascimento, Kroenke e Bezerra (2009, p. 7) "este método permite analisar um conjunto de variáveis provenientes de 
estudo qualitativos, de modo que ao final da aplicação do modelo se obtenha uma hierarquia por meio das variáveis analisadas". Assim, na fase de avaliação após a hierarquização do problema, Gartner e Gama (2005, p. 150) afirmam que "com a comparação paritária, entre os critérios e subcritérios, dependendo da hierarquia do problema, serão determinadas as importâncias relativas (pesos) dos elementos". No primeiro passo, para aplicação do método é necessário estabelecer uma matriz de preferências ou prioridades por meio de julgamentos quantificados, par a par, ou seja, atribuindo pesos para cada um dos elementos. Para o cálculo dos parâmetros, neste estudo atribuíram-se os pesos à média de cada questão calculada anteriormente, dividindo-se sempre coluna por linha e linha por coluna até completar a matriz.

A Tabela 2 demonstra o resultado da comparação par a par.

Tabela 2: Comparação par a par da matriz resultante da análise de conteúdo

\begin{tabular}{|c|c|c|c|c|c|c|c|c|c|c|c|c|c|c|c|c|c|c|c|c|c|c|c|c|}
\hline & 1 & & 3 & V4 & 5 & 6 & $\mathrm{V7}$ & V8 & 9 & 10 & 11 & 12 & 13 & 14 & 15 & 16 & 17 & 18 & 19 & 20 & 21 & $\sqrt{22}$ & $\sqrt{23}$ & 24 \\
\hline 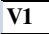 & 1,00 & 61 & 68 & 81 & 65 &, 94 & 71 & 71 & 94 & 77 & 68 & 13 & 89 & 65 & 77 & 21 & 21 & 13 & 21 & 61 & 94 & 0,68 & 00 & 0,77 \\
\hline & 65 & 00 & 12 & 33 & 08 & 56 & 17 & 17 & 56 & 27 & 12 & 87 & 47 & 08 & 27 & 2,00 & 00 & 87 & 00 & 00 & ,56 & 12 & 65 & ,27 \\
\hline V3 & & & & & & & & & & & & & & & & & & & & & & 00 & & \\
\hline V4 & 24 & & 088 & 1,0 & $0 \perp$ & & (2) & & & 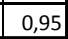 & & & 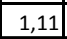 & & 0,95 & | & & 1,40 & 年 & & 17 & , 84 & & \\
\hline 5 & 53 & 93 & 1,04 & 24 & 00 & 1,44 & 88 & 1,08 & 44 & 18 & 1,04 & 73 & 37 & 00 & 18 & 86 & 86 & 73 & 86 & 93 & 44 & 1,04 & & 1,18 \\
\hline V6 & 06 & 64 & 0,7 & 0,86 & 69 & & 0,75 & 75 & 1,00 & 82 & 72 & 20 & 95 & 69 & 82 & 29 & 29 & 20 & 29 & 64 & 00 & 0,72 & 06 & 82 \\
\hline V7 & 41 & 86 & 0,96 & 1,14 & ,92 & 1,33 & 1,00 & 1,00 & & 0 & & & 20 & 0,52 & 1,05 & | & & 1,00 & 71 & & כבכ, & , & & \\
\hline V8 & 41 & & 96 & 14 & 92 & & 1,00 & & & & & & & & & & & & & & & ,96 & & \\
\hline 9 & 06 &, 64 & 0,72 & 0,86 & 0,69 & 1,00 & 0,75 & 0,75 & 1,00 & 0,82 & 72 & 1,20 & 0,95 & 69 & 0,82 & 1,29 & 29 & 20 & 1,29 & 64 & 00 & 0,72 & 06 & 82 \\
\hline 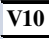 & 29 & 79 & 0 & 05 & 85 & & 0,92 & 0,92 & 1,22 & 00 & 88 & & 16 &, 85 & 00 & 57 & ונונו & 47 & 57 & & 22 & 8,88 & & 00 \\
\hline \begin{tabular}{|l|l} 
V11 \\
\end{tabular} & 47 & & 1, & 1,19 & 0 & & 1,04 & & & & & & & & & & & & & & & ,00 & & \\
\hline V12 & 8,88 & 54 & 0,60 & 0,71 & 0,58 & 0,83 & 0,63 & 63 & 0,83 & 0,68 & ,60 & 1,00 & 0,79 & ,58 & 0,68 & 1,07 & ,07. & 1,00 & 1,07 & , ,54 & , ,83 & 0,60 & 88 & 68 \\
\hline 3 & 12 & 68 & 0,76 & 0,90 & 73 & 06 & 0,79 & 79 & 06 & 86 & 76 & 27 & 00 & 73 & ,86 & 36 & 36, & 27 & ,36 & 68 & 06 & 0,76 & 12 & 86 \\
\hline V14 & & & 1, & 1,24 &, 00 & & 1,0 & & & & & & & & & & & & 1,86 & & & 04 & & \\
\hline $\begin{array}{l}\text { V15 } \\
\end{array}$ & 29 &, 79 & 0,8 & 1,05 & 0,85 & 1 & 0,92 & 92 & 1,22 & 1,00 & 88 & 1,47 & 1,16 & 85 & 1,00 & 1,57 & 57 & 47 & 1,57 & 79 & 22 & 0,88 & 29 & \\
\hline 16 & 82 & 0,50 & 0,56 & 0,67 & 0,54 & 0,78 & 0,58 & 0,58 & 0,78 &, 64 & 56 & 93 & 74 & 54 & 64 & 00 & 1,00 & 93 & 00 & 50 & 78 & 0,56 & 82 & 64 \\
\hline $\begin{array}{l}\text { V17 } \\
\end{array}$ & 0,82 & & 0, & 0,67 & 0,54 & & 0,58 & & 0,78 &, 04 & & & , 14 & & 04 & 00 & & & 00 & & 0,78 &, 56 & & \\
\hline V18 & 0,88 & 0,54 & 0,60 & 0,71 & 0,58 & 0,8 & 0,63 & 63 & 0,83 & 0,68 & 60 & 1,00 & 0,79 &, 58 & 0,68 & 1,07 & 07 & 1,00 & 07 & 0,54 & 33 & 0,60 & 38 & \\
\hline 19 & 0,82 & 0,50 & 0,56 & 0,67 & 0,54 & 0,78 & 0,58 & 0,58 & 0,78 & 0,64 & 0,56 & 0,93 & 0,74 & 0,54 & 0,64 & 1,00 & 1,00 & 0,93 & 1,00 & 0,50 & 78 & 0,56 & 82 & 64 \\
\hline $\mathbf{V 2 0}$ & 1,65 & - & 1,1 & 1,33 & 1,08 & 1,5 & 1,17 & 17 & 1,56 & 1,27 & 12 & 37 & 1,47 & 08 & 27 & 2,00 & 00 & 87 & 00 & 00 & 56 & 1,12 & 65 & 27 \\
\hline V21 & 1,06 & | & 0,72 & 0,86 & 0,69 & 1 & 0,75 & 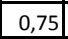 & 1 & 0,82 & 0,72 & & 0,95 & 0,69 & 82 & 29 & 1,29 & 20 & 29 & 64 & 00 &, 72 & 06 & 82 \\
\hline V22 & 1,47 & 0,89 & 1,0 & 1,19 & 0,96 & 1,39 & 1,04 & & 1,39 & 1,14 & 1,00 & 1,67 & 1,32 & & 1,14 & 1,79 & & 1,67 & 1,79 & & 39 & 1,00 & 47 & \\
\hline $\mathrm{V} 23$ & 1,00 & 0,61 & 0,6 & 0,81 & 0,65 & 0,9 & 0,71 & 0,71 & 0,94 & 0,77 & 68 & 1,13 & 0,89 & 0,65 & 0,77 & 1,21 & 1,21 & 1,13 & 1,21 & 0,61 & 0,94 & 0,68 & 1,00 & 0,77 \\
\hline 24 & 29 &, 79 & ,88 & 1,05 & 0,85 & 22 & 0,92 & 0,92 & 1,22 & 1,00 & 0,88 & 1,47 & 1,16 & 0,85 & 1,00 & 1,57 & 1,57 & 1,47 & 1,57 & - & 1,22 & 0,88 & 1,29 & 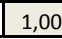 \\
\hline
\end{tabular}

Fonte: Dados da pesquisa.

No segundo passo, realizou-se a normalização dos dados desta matriz de comparações para que se pudesse analisá-la. Para esta normalização, foi necessário considerar o somatório dos pesos individuais de cada coluna, que resultou na matriz generalizada. Para tanto, o terceiro passo apresenta a matriz normalizada, que tornou possível estabelecer os pesos relativos de cada atributo a ser analisado. Para tal, considerou-se o somatório dos pesos individuais de cada linha da matriz. Gartner e Gama (2005, p.150) destacam que "a partir das importâncias dos critérios e os níveis de preferência das alternativas, parte para a valoração global de cada uma das alternativas, por uma operação de soma ponderada". 


\section{Tabela 3: Normalização da matriz}

\begin{tabular}{|c|c|c|c|c|c|c|c|c|c|c|c|c|c|c|c|c|c|c|c|c|c|c|c|c|}
\hline & & & & & & & V7 & V8 & & 10 & $\pi$ & 2 & 13 & 14 & 15 & 16 & 17 & 18 & 19 & 20 & 21 & 22 & 23 & V24 \\
\hline V1 & & & & & & & & & & & & & 03 & 03 & 03 & 03 & 03 & & & 03 & & 1,03 & ,03 & \\
\hline & & & & & & & & & & & & & & & & & & & & & & & & \\
\hline & & & & & & & & & & & & & 05 & 05 & 05 & 0,05 & 05 & & 0,0 & 05 & & U. & & 05 \\
\hline & & & & & & & & & & & & & & 04 & & 0,04 & & & , & & & & & 0,04 \\
\hline & & & & & & & & & & & & & & & & & & & & & & & & 05 \\
\hline & & & & 0,04 & 04 & 04 & 04 & & 4 & 04 & 0 , & & 04 & 04 & 84 & 0,04 & 04 & 04 & & 04 & .04 & & & 0,04 \\
\hline & & & & & & & 05 & & & & & & 05 & 0,05 & 05 & 0,0 & 05 & 05 & 0, & 05 &, 0 & 0,0 & . & 0,05 \\
\hline & & & & & & & & & & & & & & & & 0,0 & & & & & & & & 0,0 \\
\hline & & & & & & & & & & & & & 04 & & & 0,04 & & & & & & & & 0,04 \\
\hline & & & & & & & 4 & & 04 & 04 & 04 & 04 & 04 & \begin{tabular}{|l} 
\\
\end{tabular} & 04 & 0,0 & 04 & 04 & $0, \mathrm{c}$ & 04 &, 04 & & & 0,04 \\
\hline & & & & & & & & & & & & & & & & & & & & & & & & 0,05 \\
\hline & & & & & & & & & & & & & & & & 0, & & & & & & & & 0, \\
\hline & & & 04 & & & & 04 & & , 04 & & 0,04 & & 0,04 & 0,04 & & 0,04 & 0,04 & & 0, & 04 & & & & 0 \\
\hline 4 & 05 & & 05 & 0,05 & 0,05 & 05 & 05 & 0,05 & 05 & 05 & 0,05 & 3 & 0,05 & 0,05 & 05 & 0,05 & 05 & 05 & 0,0 & 05 &, 05 & 0,05 & , & 0,05 \\
\hline & & & & & & & & & & & & & & & & & & & & & & & & 04 \\
\hline & & & & & & & & & & & & & 0,03 & & & 0,0 & & & & & & & & 0,0 \\
\hline & & & & 0, & & & 03 & & 0, & & 0,03 & & 03 & 0, & 03 & 0,0 & & & & & & & & 0,03 \\
\hline $\mathrm{V} 18$ & 03 & & & 0, & & 0,03 & 03 & & 03 & 33 & 0,03 & & 0,03 & 03 & 03 & 0,03 & 3 & 03 & & 03 & 03 & & 03 & 0,03 \\
\hline & & & & & & & & & & & & & & & & 0, & & & & & & & & 0,03 \\
\hline$\sqrt{2}$ & 0,06 & & & 0, & 0, & & 0, & 0 & 0, & & 0, & 0 & 0,06 & 0 , & 00 & $0, \mathrm{C}$ & & 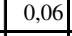 & & & & & & 0,0 \\
\hline$\sqrt{21}$ & & & & & & & 84 & & & & & & 0,04 & & & & & & & & & & & 04 \\
\hline $\mathrm{V} 22$ & ,05 & & 05 & 0, & 0, & & 0,05 & & 5 & & 0,05 & 55 & 05 & 0,05 & 05 & 05 & 5 & 05 & & 5 & 05 & & 05 &, 05 \\
\hline & 0, & & & 0, & & & 0, & & 0 & & 0, & & 0, & 0, & & 0,0 & 0 & & 0, & & & & 3 & 0,03 \\
\hline \multirow[t]{2}{*}{$\mathrm{V} 24$} & 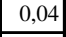 & & & 0, & & & 0,04 & & & & 0,0 & & 0 & & & 0,0 & & & & & & & & 0,04 \\
\hline & 1,00 & & & & & & 00 & & & & & & & ,00 & & & 00 & 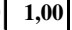 & & , 00 & & 1,00 & , 00 & 1,0 \\
\hline
\end{tabular}

Fonte: Dados da pesquisa.

No quarto passo, de posse da matriz foi possível obter uma pontuação por meio da multiplicação da matriz inicial, ou seja, a matriz composta pela evidenciação das informações com a média por linha das variáveis na matriz normalizada. Assim, neste estudo, a pontuação se refere a uma avaliação do nível de evidenciação das informações ambientais das empresas analisadas, portanto, considerando este resultado, basta classificar as empresas conforme suas pontuações gerando uma hierarquia, ou seja, um ranking das evidenciações.

\section{ANÁLISE DOS DADOS}

Nesta seção, apresenta-se a caracterização das empresas analisadas, a evidenciação das informações ambientais destas companhias, de acordo com a categorização proposta pelo modelo desenvolvido com base nos indicadores de responsabilidade social empresarial do Instituto Ethos (2009) e o ranking das empresas, com base na evidenciação das questões 
relacionadas à gestão ambiental. A análise permite verificar a cultura ambiental das empresas pelos meios de divulgação.

\subsection{CARACTERIZAÇÃO DAS EMPRESAS ANALISADAS}

A caracterização das empresas demonstra como os diferentes segmentos da Bovespa estão representados no ISE e quais níveis de negociação diferenciada predominam entre as empresas do ISE, neste caso trata-se de empresas que compõem o índice do momento em que ele foi criado até a composição 2008/2009. Na Figura 2, apresentam-se os segmentos e os níveis da Bovespa das empresas estudadas.

Figura 2: Caracterização das empresas analisadas

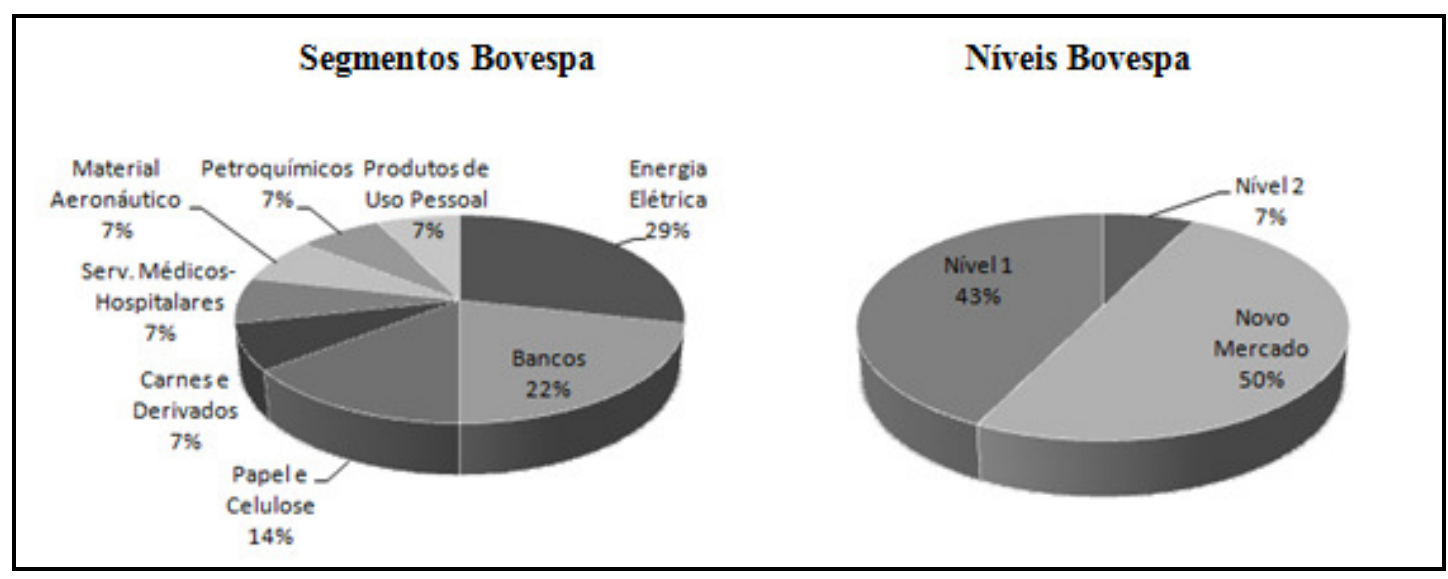

Fonte: Dados da pesquisa.

Verifica-se na Figura 2 que a maioria das empresas investigadas pertence ao setor de Energia Elétrica, sendo $29 \%$ das empresas do ISE que o compõem desde sua criação. Na sequência, o setor Bancário apresenta 22\%, ocupando o segundo lugar dentre as empresas que compõem a amostra, posteriormente encontram-se as empresas de Papel e Celulose com 14\%, com representação semelhante, tem-se o segmento de Carnes e Derivados, Serviços Médicos e Hospitalares, Material Aeronáutico, Petroquímico e Produtos de Uso Pessoal, todos com 7\%. Portanto, evidencia- se o predomínio de empresas do segmento de Energia Elétrica dentre as empresas que compõem o ISE, o que pode ser explicado pelo alto grau de exigências impostas pelos órgãos reguladores do setor, principalmente tratando-se de ações ambientais. 
Observa-se que todas as empresas que permanecem no ISE desde a primeira formação fazem parte dos níveis de governança corporativa da Bovespa, destes predominam empresas listadas no Novo Mercado e no Nível 1 de governança corporativa, sendo $50 \%$ e 43\%, respectivamente. Percebe-se que as exigências necessárias para fazer parte dos níveis de governança corporativa alinham-se a algumas exigências para compor o ISE.

\subsection{SÍNTESE DAS CATEGORIAS DE GESTÃO AMBIENTAL INVESTIGADAS}

Por meio do modelo proposto para investigação da evidenciação ambiental, foi possível analisar as categorias propostas nas empresas durante os anos de 2005 a 2008, período em que foram investigados os RAs e as homepage das empresas analisadas, a fim de vislumbrar a evidenciação das informações referentes à gestão ambiental, conforme Tabela 4.

Tabela 4: Categorias de gestão ambiental evidenciadas

\begin{tabular}{|c|c|c|c|c|c|c|c|}
\hline \multirow{2}{*}{ Categorias } & \multicolumn{5}{|c|}{ Período analisado } & \multirow{2}{*}{ Total } & \multirow{2}{*}{$\%$} \\
\hline & 2005 & 2006 & 2007 & 2008 & Sites & & \\
\hline Categoria 1: Resíduos & 17 & 27 & 24 & 26 & 35 & 129 & $25 \%$ \\
\hline Categoria 2: Materiais & 8 & 21 & 20 & 19 & 36 & 104 & $20 \%$ \\
\hline Categoria 3: Energia & 9 & 17 & 16 & 17 & 24 & 83 & $16 \%$ \\
\hline Categoria 4: Água & 5 & 11 & 11 & 13 & 25 & 65 & $12 \%$ \\
\hline Categoria 5: Transporte & 0 & 1 & 1 & 1 & 1 & 4 & $1 \%$ \\
\hline Categoria 6: Gestão & 18 & 27 & 25 & 26 & 40 & 136 & $26 \%$ \\
\hline Total & 57 & 104 & 97 & 102 & 161 & 521 & $100 \%$ \\
\hline
\end{tabular}

Fonte: Dados da pesquisa.

A Tabela 4 possibilita comparar as categorias evidenciadas na pesquisa, onde percebese que nos sites das organizações foram evidenciadas mais questões relacionadas à gestão ambiental do que nos relatórios anuais. Verificou-se o total de 161 pontos nos sites e, nos anos com maior pontuação, pouco mais de 100 pontos nos RA.

Verificou-se, ainda, que em 2006 houve um aumento mais significativo de evidenciação por parte das empresas, passando de 57 pontos em 2005, para 104 em 2006. No decorrer dos anos analisados, com base no modelo proposto, as empresas ficaram perto dos 100 pontos em cada ano. Destacando-se as Categorias 6 - Gestão, 1 - Resíduos e 2 - Materiais, que acumularam respectivamente 136, 129 e 104 pontos na análise total, o que representa mais de 
$70 \%$ do total das 6 categorias analisadas na evidenciação da gestão ambiental das empresas que compõem o ISE desde sua criação. Esse resultado corrobora com Leite, Ribeiro e Pacheco (2007) que destacaram a importância da divulgação de informações referentes à organização, ou seja, observa-se um aumento contínuo na divulgação de informações que demonstram a preocupação das empresas com relação ao meio ambiente. Essa atitude faz-se necessária devido à sociedade demonstrar-se cada vez mais crítica e preocupada com o comportamento das organizações com relação ao futuro.

Os resultados desta pesquisa corroboram com os achados de Machado e Giombelli (1997) que destacaram que a variável ambiental pode ser percebida por meio da identificação de técnicas e políticas que visam à preservação do meio ambiente. Sendo a variável ambiental operacionalizada dentro da empresa, infere-se que ela passa a fazer parte da cultura da organização. De acordo com Freitas (1991), a cultura organizacional pode ser entendida como um mecanismo que objetiva conformar condutas, igualar maneiras de pensar e viver na entidade, projetar imagem positiva da organização, buscando a igualdade e dirimindo diferenças.

O modelo utilizado na pesquisa abrange 24 subcategorias, nas 6 categorias demonstradas, a amostra possui 14 empresas que fazem parte do ISE desde o início, sendo realizada análise de 4 anos nos RA e dos sites das empresas, assim a possibilidade máxima seria de 1.680 observações. Portanto, o modelo apresenta um máximo de 1680 pontos, a pesquisa chega a 521 observações que correspondem a $31 \%$ do total possível de evidenciação ambiental nas empresas que compõem o ISE desde sua primeira formação.

\subsection{EVIDENCIAÇÃO AMBIENTAL NOS RELATÓRIOS DE ADMINISTRAÇÃO}

Apresentam-se, a seguir, as empresas analisadas e seus respectivos indicadores de evidenciação da gestão ambiental, demonstrando sua evolução nos períodos de análise dos relatórios de administração. A Figura 3 representa o ranking de classificação das empresas analisadas por ano.

Figura 3: Ranking da evidenciação nos RAs das empresas analisadas 


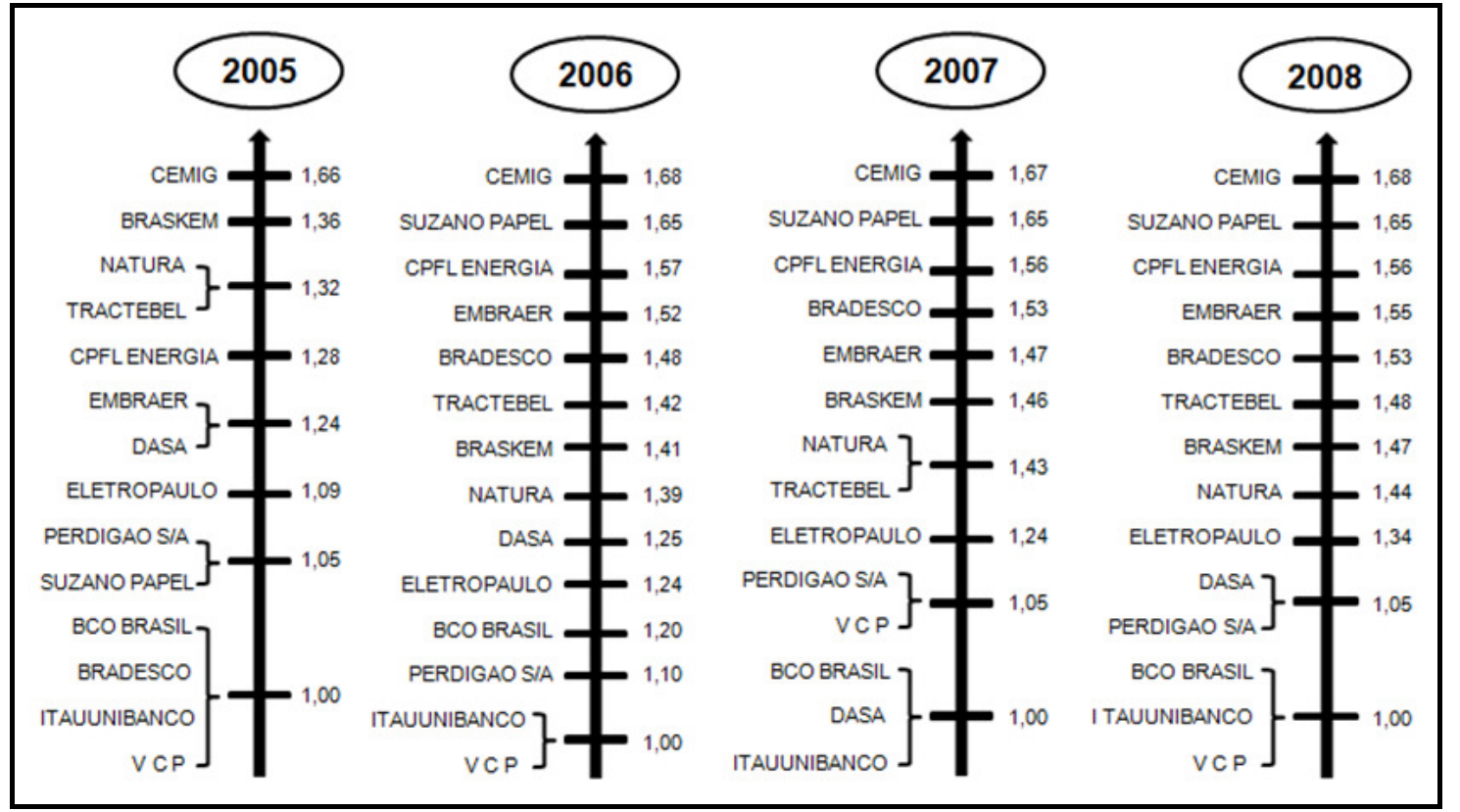

Fonte: Dados da pesquisa.

Os dados expostos na Figura 3 permitem acompanhar o desenvolvimento das empresas em relação à evidenciação das questões que dizem respeito à gestão ambiental nos RA. Destaca-se a permanência da Cemig no topo do ranking durante os quatro anos, a organização obteve maior pontuação nos critérios verificados relativos à evidenciação ambiental, mantendo-se constante durante os anos. A Suzano Papel ficou em segundo no ranking nos últimos três anos, com um índice de 1,65, obtendo grande evolução de 2005, quando possuía apenas 1,05.

O Bradesco, que em 2005 apresentava um índice baixo (1,00), não evidenciou informações no RA sobre gestão ambiental, porém, assim como a Suzano, o banco elevou seu índice no período seguinte. 0 índice chegou a 1,48 e continuou crescendo nos anos seguintes, mantendo o Bradesco entre as empresas com os maiores índices de evidenciação ambiental com base no modelo de análise proposto na pesquisa.

Na outra ponta do ranking, com nenhuma evidenciação ou com um índice muito baixo de evidenciação ambiental nos relatórios de administração durante os quatro anos, aparecem as empresas VCP, Itaú Unibanco, Banco do Brasil, Perdigão. Seguindo uma tendência contrária à maioria das empresas do estudo, a DASA apresenta nos primeiros dois anos os índices de 1,24 e 1,25, respectivamente, já no terceiro ano não evidencia nenhuma informação sobre gestão ambiental no Relatório de Administração e no último ano, o índice é de 1,05.

A análise dos relatórios de administração das empresas que compõem o ISE desde sua primeira formação permite inferir que existe uma tendência ao aumento da evidenciação 
ambiental nos RA das organizações que fazem parte deste índice. A maioria das empresas possui cultura na evidenciação, não levando a grandes variabilidades dos resultados, com o passar dos anos verificados neste estudo. Dessa maneira, é possível observar a cultura da organização com base nas suas atitudes, pois de acordo com Gray e Bebbington (2001), a cultura organizacional define o nível de evidenciação ambiental nos relatórios de uma organização, neste caso nos relatórios anuais.

\subsection{EVIDENCIAÇÃO AMBIENTAL NOS RAS E SITES DAS ORGANIZAÇÕES}

Os sites das organizações tornaram-se ferramentas essenciais nas estratégias empresariais nos últimos anos. Passam a disponibilizar grande parte de suas informações de cunho social e ambiental nas suas páginas. Na Figura 4, pode-se comparar a evidenciação nos relatórios de administração e nos sites das empresas que estão no ISE desde sua criação.

Figura 4: Ranking geral da evidenciação ambiental

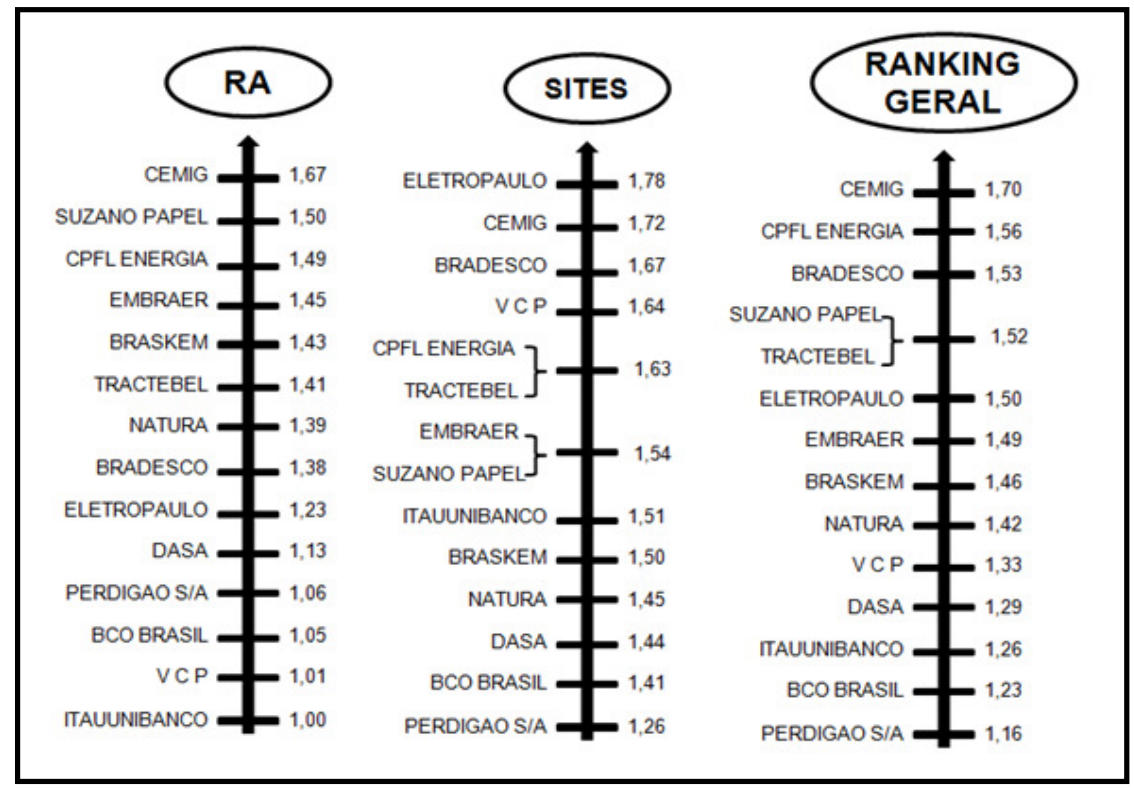

Fonte: Dados da pesquisa.

Na Figura 4, foram elaborados três rankings de evidenciação ambiental nas empresas que fizeram parte do ISE em todos os anos. Denota-se que a Cemig perdeu a supremacia da evidenciação nos relatórios de administração para a Eletropaulo, que obteve maior índice na evidenciação realizada por meio de sites. No ranking geral, pode-se perceber que a Cemig obteve 
o índice de 1,70, demonstrando evidenciar questões ambientais, tanto nos RA quanto no site da empresa.

O Itaú Unibanco não apresentou nenhuma evidenciação ambiental em seus relatórios de administração durante os quatro anos analisados, porém o site da empresa evidencia muitas informações ambientais, atingindo um índice de 1,51\%, ultrapassando diversas empresas da amostra que estavam a sua frente na evidenciação dos RA.

No ranking geral, a Perdigão ficou com o índice mais baixo, puxado pela pouca evidenciação das informações ambientais em seu site, que em conjunto com o baixo índice de evidenciação nos relatórios anuais, chegaram a 1,16.

Todas as empresas apresentaram um índice de evidenciação maior no site de cada organização, sendo muito superiores as informações apresentadas nos relatórios de administração. Pode-se inferir que as companhias utilizam mais os sites do que os relatórios de administração para expressar suas atitudes e projetos relacionados à gestão ambiental. Neste contexto, infere-se que a cultura organizacional pelo site da mesma, ou seja, a cultura é representada por artefatos e entre os artefatos estão os Artefatos Físicos, ou seja, a arte da organização que incluem símbolos, documentos, jornais, folders, cartazes, informativos que evidenciam a preocupação da organização com relação ao meio ambiente (MACHADO; GIOMBELLI, 1997 apud KILMAN, et. al, 1988).

\section{CONCLUSÕES}

O estudo objetivou verificar a evolução do disclosure ambiental nas organizações que compõem o ISE desde a sua primeira formação. Para atender ao objetivo central foi desenvolvido um modelo com base nos indicadores de responsabilidade social empresarial do Instituto Ethos, permitindo analisar a evidenciação da gestão ambiental da amostra da pesquisa.

Ao caracterizar as empresas que fazem parte do Índice de Sustentabilidade Empresarial desde sua criação, pôde-se verificar que o setor de Energia Elétrica possui o maior número de empresas, sendo $29 \%$ das companhias com esta característica. Verificou-se também que predominam as empresas listadas nos níveis de governança corporativa da Bovespa, sendo todas empresas listadas a partir do critério de permanência no índice desde a criação. 
Portanto, pode-se inferir que as exigências da governança corporativa e o alto grau de exigências impostas pelos órgãos reguladores do setor de Energia Elétrica, principalmente tratando-se de questões ambientais, têm influência na contínua permanência de empresas com estas características na composição do ISE. O fato pode ser explicado pelo índice ser composto por ações de empresas com reconhecido comprometimento com a responsabilidade social e a sustentabilidade empresarial.

O modelo proposto para investigação da evidenciação ambiental permitiu verificar que em 2006 ocorreu aumento mais significativo de evidenciação por parte das empresas. No decorrer dos anos analisados, destacaram-se as Categorias 6 - Gestão, 1 - Resíduos e 2 - Materiais, como as mais evidenciadas pelas companhias. Observa-se um aumento contínuo na divulgação de informações que demonstram a preocupação das empresas com relação ao meio ambiente. Atendendo assim à sociedade, respaldando sua crescente cobrança por transparência nas atitudes relacionadas ao meio ambiente. Desta forma, incorporando-se a cultura da empresa, sendo operacionalizada e evidenciada pela organização.

Por meio do modelo utilizado, poder-se-ia chegar ao máximo de 1.680 observações, a análise dos sites das empresas e relatórios de administração chegou a 521 observações, que correspondem a 31\% do total possível de evidenciação ambiental nas empresas que compõem o ISE desde sua primeira formação.

Infere-se que as empresas que compõem o ISE desde sua primeira formação possuem tendência ao aumento da evidenciação ambiental nos RA. A maioria das organizações possui cultura na evidenciação, não levando a grandes variabilidades dos resultados com o passar dos anos.

Por fim, os rankings de evidenciação ambiental demonstraram que todas as empresas apresentaram um índice de evidenciação maior no site de cada organização, sendo muito superiores às informações apresentadas nos relatórios de administração. Pode-se inferir que as companhias utilizam mais os sites do que os relatórios de administração para expressar suas atitudes e projetos relacionados à gestão ambiental e, consequentemente, é possível observar também a cultura organizacional pelo site da mesma, ou seja, a cultura é representada por artefatos e entre eles estão os Artefatos Físicos, que incluem documentos, jornais, folders, cartazes, informativos que evidenciam a preocupação da organização com relação ao meio ambiente. 
Conclui-se que as companhias que fazem parte do Índice de Sustentabilidade Empresarial desde sua primeira formação detectou-se indícios de cultura ao evidenciar as informações relacionadas à gestão ambiental das empresas, utilizando-se mais dos sites de cada companhia, do que dos relatórios de administração integrantes das informações financeiras padronizadas. Acredita-se que por fazer parte de um índice que considera questões ambientais na escolha das empresas participantes, estas organizações prezam a transparência de informações de gestão ambiental. Sendo através dos sites ou mesmo nos relatórios de administração que acabam sendo utilizados como fontes de informação para tomada de decisão dos diversos usuários.

Futuras pesquisas abordando a gestão ambiental podem ser realizadas objetivando comparar as empresas que deixam de fazer parte do Índice de Sustentabilidade Empresarial da BM\&FBovespa, com as que permanecem desde a primeira composição, a fim de verificar diferenças de evidenciação, contribuindo com este e com os demais estudos sobre o tema.

\title{
ENVIRONMENTAL DISCLOSURE: A STUDY ABOUT EVOLUTION IN COMPANIES COMPRISING THE ENVIRONMENTAL SUSTAINABILITY INDEX
}

\begin{abstract}
This research aimed at assessing the evolution of environmental disclosure in the organizations that comprise the ISE since its first incarnation. In the methodology, we chose a descriptive research through a content analysis with a qualitative and quantitative approach. Presenting as a theoretical underpinning rapid approach to Environmental Management, Environmental Sustainability Index (ISE) and Categories Cultural and Environmental Variables. We developed a model based on the indicators of corporate social responsibility of the Ethos Institute (2009) and later were organized into companies rankings, by applying the Analytic Hierarchy Process (AHP). The sample is made up of companies that comprise the ISE BM\&FBovespa from the start, totaling 14 participating companies. The results show that in 2006 there was a significant increase in disclosure by companies. It found a steady increase in the disclosure of information that demonstrate the business concern with respect to the environment. Thus meeting the demands of society, supporting their recovery by increasing transparency in attitudes to the environment. Thus, incorporating the company's culture, being operationalized and evidenced by the organization. The rankings reveal that the companies had a higher rate of disclosure in the sites,
\end{abstract}


much higher than the information the report of management. It also infers that companies use their website to express their attitudes and projects related to environmental management.

Keywords: Environmental disclosure. Environmental responsibility. Corporate Sustainability Index.

\section{REFERÊNCIAS}

ALÉSSIO, S. C.; DALFOVO, O.; DALFOVO, M. S.; FIALHO, F. A. P. Pesquisa de clima organizacional em empresas de desenvolvimento de software de Blumenau - SC. Revista Estratégia \& Negócio, v. 2, p. 96-116, 2009.

AQUINO, W.; SANTANA, A. C. Evidenciação. Caderno de Estudos, São Paulo: FIPECAFI n. 5. jun., 1992.

ANDRADE, R.; TACHIZAWA, T.; CARVALHO, A. B. Gestão ambiental: enfoque estratégico aplicado ao desenvolvimento sustentável. São Paulo: Makron Books, 2002. 246 p.

AZEVEDO, T. C.; CRUZ, C. F. Balanço Social como instrumento para demonstrar a responsabilidade social das entidades: Uma discussão quanto à elaboração, padronização e regulamentação.

Revista Pensar Contábil, v.8, p.13-20, 2006.

BARDIN, L. Análise de conteúdo. Lisboa: Edições 70, 2004. 225p.

BOLSA DE VALORES DE SÃO PAULO (BOVESPA). Disponível em: www.bovespa.com.br. Acesso em: 3 de set. 2009.

ISE - Índice de Sustentabilidade Empresarial. Disponível em: www.bovespa.com.br. Acesso em: 22 de out. de 2009.

CARAZZA, R. I. Gestão Ambiental e mudanças da estrutura organizacional. Revista RAE-Eletrônica, v. $2, \cdot$ n. $2 \cdot$ jul-dez/2003.

CALIXTO, L. Uma análise da evidenciação ambiental de companhias brasileiras de 1997 a 2005. In: Congresso Brasileiro de Custos, 13., 2006, Belo Horizonte. Anais... Belo Horizonte: CBC, 2006. CDROM.

FREITAS, M. E. Cultura Organizacional. São Paulo: Makron Books, 1991.

FLEURY, M. T. L.; FISCHER, R. M. Cultura e Poder nas Organizações. São Paulo: Atlas, 1989. GARTNER, I. R.; GAMA, M. L. Avaliação Multicriterial dos Impactos Ambientais da Suinocultura no Distrito Federal: um estudo de caso. Organizações Rurais \& Agronegócios, v.7, n.2, p.148-161, 2005. 
GRAY, R.; BEBBINGTON, J. Accounting for the Environment. 2 ed. Londres: Sage, 2001.

GONÇALVES, S. S., HELIODORO, P. A. A.. Contabilidade Ambiental como um Novo Paradigma. Revista Universo Contábil, n.1, p. 84-96, 2005.

GONÇALVES, R. C. M. G.; PIRANI, D. C.; BORGER, F. G. Qualidade das Informações sobre Responsabilidade Social Divulgadas pelos Bancos Privados com Ações Listadas no Índice de Sustentabilidade Empresarial da Bovespa. In: Encontro Nacional da Associação de Pós-Graduação e Pesquisa em Administração, 31, 2007, Rio de Janeiro. Anais... Salvador: ANPAD, 2007. CD-ROM.

INSTITUTO ETHOS. Indicadores Ethos de responsabilidade social empresarial. 2009. Disponível em: <www.ethos.org.br>. Acesso em: 22 de out. de 2009.

LARAIA, R. B. Cultura: um conceito antropológico. Rio de Janeiro: Jorge Zahar Ed., 2002.

LEITE, R. M.; RIBEIRO, R. R. M.; PACHECO, V. Evidenciação do Passivo Ambiental e Interação das Empresas com o meio Ambiente. In: Congresso ANPCONT, 1., 2007. Gramado. Anais... Gramado ANPCONT: 2007. CD-ROM.

MACHADO, D. P. N. ; GIOMBELLI, V. Preservação Ambiental e Cultura Organizacional: Um diagnóstico da região de Blumenau. In: ENEGEP, 17., 1997, Gramado. Anais... Gramado: ABEPRO, 1997. CD-ROM.

MACHADO, D. D. P. N. Inovação e cultura organizacional: um estudo dos elementos culturais que fazem parte de um ambiente inovador. 2004. 181f. Tese (Doutorado em Administração) - Escola de Administração de Empresas de São Paulo, FGV, São Paulo, 2004.

MAKOWER, J. Business for social responsibility: beyond the bottom line: putting social responsibility to work for your business and the World. New York: Simon \& Schuster, 1994.

\section{MELLO NETO, F. P.; FROES, C. Responsabilidade Social e cidadania empresarial: a} administração do terceiro setor. Rio de Janeiro: Qualitymark, 1999.

MOREIRA, M. S. Estratégia e Implantação do Sistema de Gestão Ambiental: Modelo ISO 14.000. Nova Lima: INDG Tecnologia e Serviços Ltda., 2006.

MOURA, L. A. A. Qualidade e Gestão ambiental: Sustentabilidade e Implantação da ISO 14.001. 5. ed. São Paulo: Editora Juarez de Oliveira, 2008.

NASCIMENTO, S.; KROENKE, A.; BEZERRA, F. A. Nível de evidenciação das empresas de Papel e Celulose que compõem o Índice de Sustentabilidade Empresarial (ISE). In: Congresso Brasileiro de Custos, 16., 2009, Fortaleza. Anais... São Leopoldo: CBC, 2009. CD-ROM.

NOSSA, V. Disclosure ambiental: uma análise do conteúdo dos relatórios ambientais de empresas do setor de papel e celulose em nível internacional. 2002. Tese (Doutorado em Ciências Contábeis) Programa de Pós-Graduação em Controladoria e Contabilidade, Universidade de São Paulo, São Paulo, 2002. 
RAUPP, F. M.; BEUREN, I. M. Caracterização da Pesquisa em Contabilidade. In: BEUREN, Ilse Maria (Org). Como elaborar trabalhos monográficos em contabilidade: teoria e prática. 3. ed. São Paulo: Atlas, 2008.

REZENDE, I. A. C.; SANTOS, L. S. R. Análise da Rentabilidade e Performance dos Investimentos Socialmente Responsáveis: um estudo empírico no mercado brasileiro. In: Encontro da Associação Nacional de Pós-Graduação e Pesquisa em Administração, 30., 2006, Salvador. Anais... Salvador: EnANPAD, 2006. CD-ROM.

RIBEIRO, M. S. Contabilidade ambiental. São Paulo: Saraiva: 2005.

RICHARDSON, R. J. Pesquisa Social: métodos e técnicas. 2. ed. São Paulo: Atlas, 1989.

ROVER, S.; BORBA, J. A.; BORGERT, A. Como as Empresas Classificadas no Índice de Sustentabilidade Empresarial (ISE) Evidenciam os Custos e Investimentos Ambientais? Revista de Custos e @gronegócio online, v. 4, n. 1, jan/abr, 2008.

SILVEIRA, N. C. Aplicação dos indicadores de responsabilidade social empresarial: estudo de caso com uma empresa de economia de comunhão. 2008. 226 f. Dissertação de Mestrado. Universidade de São Paulo. Faculdade de Economia, Administração e contabilidade de Ribeirão Preto, 2008.

SMIRCICH, L. Concepts of Culture and Organizacional Analysis. Administrative Science Quaterly, v.28, n.3, p.339-358, 1983.

TRIVIÑOS, A. N. S. Introdução à pesquisa em ciências sociais: a pesquisa qualitativa em educação. São Paulo: Atlas, 1987. 175 p.

TROMPENAARS, F. Nas Ondas da Cultura. São Paulo: Educator, 1994.

VALLE, C. E. Qualidade ambiental: ISSO 14.000. 5. ed. São Paulo: Editora Senac São Paulo, 2004.

VAZ, A. C.; GONÇALVES, R. S.; NIYAMA, J. K; GONÇALVES, A. O. Análise comparativa sobre informações voluntárias divulgadas: o social disclosure das empresas latino-americanas listadas na Nyse. In: Encontro da Associação Nacional de Pós-Graduação e Pesquisa em Administração, 32., 2008, Rio de Janeiro. Anais... Rio de Janeiro: ANPAD, 2008. CD-ROM.

WERNKE, R. Custos ambientais: uma abordagem teórica com ênfase na obtenção de vantagem competitiva. Revista de Contabilidade do CRC-SP, v.5, n.15, p.40-49, 2001. 